Gefässchirurgie 2021 $26: 544$

https://doi.org/10.1007/s00772-021-00839-0

Online publiziert: 15. Oktober 2021

(c) Der/die Autor(en) 2021
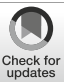

\section{Erratum zu: Leitlinien-Check für die Shuntchirurgie 2021}

\author{
Daniel Becker ${ }^{1}$. Andrej Isaak ${ }^{2}$. Jürg Schmidli · Matthias K. Widmer ${ }^{1}$ \\ ' Universitätsklinik für Herz- und Gefässchirurgie, Inselspital, Universität Bern, Bern, Schweiz \\ ${ }^{2}$ Universitäres Gefässzentrum Aarau/Basel, Kantonsspital Aarau, Aarau, Schweiz
}

\section{Erratum zu: \\ Gefässchirurgie 2021 \\ https://doi.org/10.1007/s00772-021- \\ 00820-x}

In der ursprünglichen Version des Beitrags waren leider zwei Fehler enthalten: Der Autor Andrej Isaak war fälschlicherweise der Affiliation 1 zugeordnet, und sein Nachname war falsch geschrieben.

Der Originalbeitrag wurde korrigiert.

\section{Korrespondenzadresse}

Dr. med. Daniel Becker

Universitätsklinikfür Herz- und Gefässchirurgie, Inselspital, Universität Bern

Freiburgstrasse 8, 3010 Bern, Schweiz

daniel.becker@insel.ch

Open Access. Dieser Artikel wird unter der Creative Commons Namensnennung 4.0 International Lizenz veröffentlicht, welche die Nutzung, Vervielfältigung, Bearbeitung, Verbreitung und Wiedergabe in jeglichem Medium und Format erlaubt, sofern Sie den/die ursprünglichen Autor(en) und die Quelle ordnungsgemäß nennen, einen Link zur Creative Commons Lizenz beifügen und angeben, ob Änderungen vorgenommen wurden.

Die in diesem Artikel enthaltenen Bilder und sonstiges Drittmaterial unterliegen ebenfalls der genannten Creative Commons Lizenz, sofern sich aus der Abbildungslegende nichts anderes ergibt. Sofern das betreffende Material nicht unter der genannten Creative Commons Lizenz steht und die betreffende Handlung nicht nach gesetzlichen Vorschriften erlaubt ist, ist für die oben aufgeführten Weiterverwendungen des $\mathrm{Ma}$ terials die Einwilligung des jeweiligen Rechteinhabers einzuholen.

Weitere Details zur Lizenz entnehmen Sie bitte der Lizenzinformation auf http://creativecommons.org/ licenses/by/4.0/deed.de. 